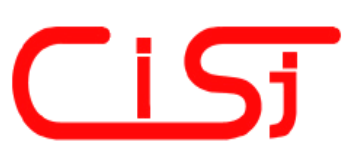

\title{
E-LEARNING ENVIRONMENT FOR THE REMOTE STUDY IN MATERIAL PROPERTIES COURSES
}

\author{
Peter Arras ${ }^{1)}$, Yelizaveta Kolot ${ }^{2)}$, Galyna Tabunshchyk ${ }^{2)}$, Tomas Kozík ${ }^{3)}$ \\ 1) Faculty of Engineering Technology, KULeuven-campus De Nayer, \\ Sint Katelijne Waver, J. P. De Nayerlaan 5, Belgium, \\ E-mail: peter.arras@kuleuven.be, http://iiw.kuleuven.be \\ ${ }^{2)}$ Software Tools Department of Zaporizhzhya National Technical University, \\ Zhukovskogo, 64, Zaporizhzhya, 69063, Ukraine, \\ E-mail: galina.tabunshchik@gmail.com, http://www.zntu.edu.ua \\ 3) Department of Technology and Information Technologies, Faculty of Education, \\ Constantine the Philosopher University in Nitra, \\ Dražovská 4, 94901 Nitra, \\ E-mail: tkozik@ukf.sk, http://www.ukf.sk
}

\begin{abstract}
In this paper a newly developed e-learning environment for the support of the study on Material Properties is presented. It was developed to support the blended learning of the material and shape stiffness. Course structure is organized in HTML content, and virtual and remote laboratories are integrated in the computer aided learning module (CALM), which support both teachers during the hand-on teaching and students during self-study. Copyright (C) Research Institute for Intelligent Computer Systems, 2013. All rights reserved.
\end{abstract}

Keywords: CALM, remote laboratory, virtual laboratory, material stiffness, shape stiffness.

\section{INTRODUCTION}

The field of material science is defined as a key knowledge area for engineers. Many - if not all innovations in modern technologies are related to the use of new materials, or new technological methods of using existing materials. However, study time in existing curricula is limited and new findings in material sciences cannot be fitted in. E_learning modules could help make up for this lack of time. This paper is devoted to the Computer Aided Learning Module (CALM) [1], developed for the supporting e-learning courses in Material Science Properties.

\section{STRUCTURE OF THE COMPUTER AIDED LEARNING MODULE}

A complete driving learning module for material sciences is constructed. The structure of it can found in Fig. 1. It is the framework in which fits the theoretical courses, and the different laboratories described.

The present remote lab in the Computer Aided Learning Module (CALM) is intended to be used to study the phenomenon of material versus shape stiffness. The CALM contains all the learning contents students are supposed to study on the subject. The CALM will be used in classroom teaching and demonstrated to instruct students on how to use the remote lab.

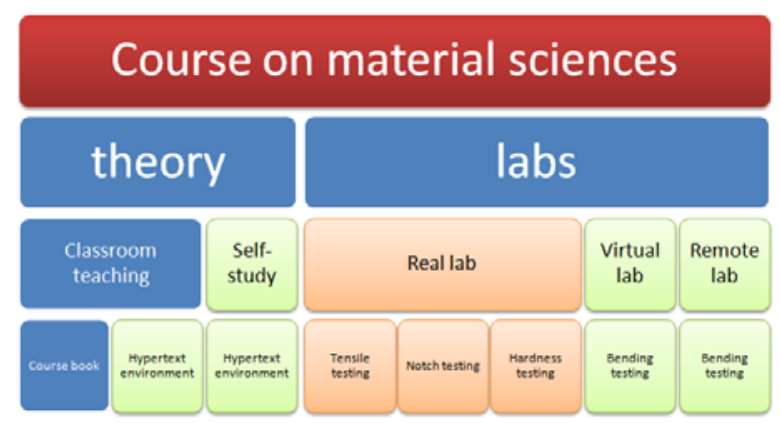

Fig. 1 - Structure of the course on material science, integrated in the CALM.

Students will study theory afterwards at their own pace, using the hypertext environment, and next simulate different combinations of materials and shapes in the virtual laboratory. Finally students can experiment on real material and shapes in the remote laboratory.

Different techniques are combined: hypertext linked contents, virtual lab (using Shockwave Flash) 
and a remote lab (controls for it using Javascript) (Fig. 2). Slideshows are provided for documentation purposes and to include the classroom presentations (Fig. 3).

The structure of the theory on the CALM reflects the materials in the student's physical course books. As such the look and feel of the e_learning environment is similar to what students experience in the classroom sessions [2].

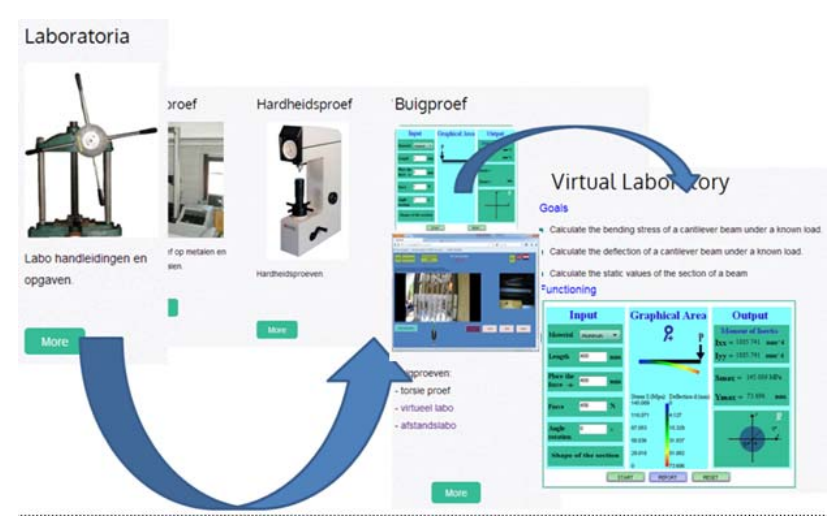

Fig. 2 - Navigation in the hypertext.

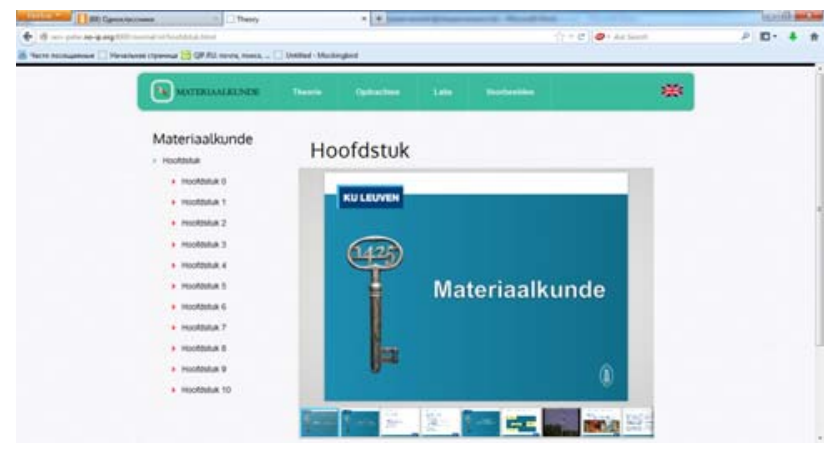

Fig. 3 - Lectures presentation.

\section{VIRTUAL LABORATORY}

The virtual laboratory is a simulation of a test in the physical laboratory for material properties study [2]. It was constructed using the basic formulas for the bending of a cantilever beam. In the virtual lab a number of specimens with standard sections can be tested. Applied force, shape is changeable to offer a wide variety of possibilities. The only limitation with the basic formulas is that asymmetrical test specimens will yield erroneous values, because bending outside the plane of the specimen is not considered in the basic formulas (Fig. 4).

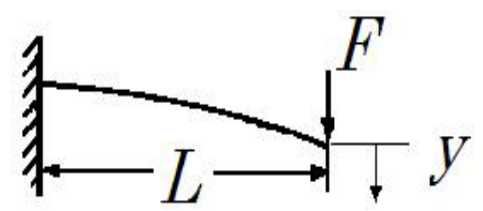

Fig. 4 - Deflection of a cantilever beam.
Used formulas for bending of a cantilever beam [3]: Maximum deflection at the free end:

$$
y=\frac{F \times L^{3}}{3 \times E \times I}
$$

Maximum bending stress in the cantilever beam (at the supported end):

$$
\sigma=\frac{F \times L}{I / v}
$$

Moment of inertia (I): e.g. of a rectangle:

$$
I=\frac{b \times h^{3}}{12 \times I}
$$

Table 1. Used symbols.

\begin{tabular}{|l|l|l|}
\hline \multicolumn{3}{|c|}{ Used symbols } \\
\hline Symbol & \multicolumn{1}{|c|}{ Name } & Unit \\
\hline E & Young's modulus & $\mathrm{MPa}$ \\
\hline I & Moment of inertia & $\mathrm{mm}^{\wedge} 4$ \\
\hline F & Load & $\mathrm{N}$ \\
\hline S & $\begin{array}{l}\text { Maximum bending stress in } \\
\text { the cross-section }\end{array}$ & $\mathrm{MPa}$ \\
\hline $\mathrm{y}$ & Maximum deflection & $\mathrm{mm}$ \\
\hline $\mathrm{L}$ & Length of beam & $\mathrm{mm}$ \\
\hline $\mathrm{v}$ & Distance to neutral fiber & $\mathrm{mm}$ \\
\hline
\end{tabular}

\subsection{FUNCTIONAL REQUIREMENTS FOR THE VIRTUAL LAB}

1. Calculation and visualization of the deflection of a cantilever beam, with measurement of deflection at the end and indication of maximum stress and force.

2. The values for different Young's modulus for a variety of materials should be chosen according to reported values [3].

3. For a variety of shapes (rectangular section, $\mathrm{H}$ beams, U-beam, hollow shapes...) the shape stiffness can be used.

4. For different orientations of the same shape (increment angles $1^{\circ}$ ) about the principal axes.

5 . For a variety of dimensions in the same shape. (cross section dimensions and length). The different values should be entered by the student experimenter.

\subsection{SUPPLEMENTARY REQUIREMENTS FOR THE VIRTUAL LAB}

Experimenting students should be able to select all different possibilities with the aid of pull down 
menus and selection panels, and dialogue boxes for dimensions.

Readings of deflection, force and stresses with the aid of look a like analogue meters.

Force should be applicable with the aid of a slider bar, and real time adjustment of readings should be taken care of.

Readings should be exportable: available in a window from which to copy, together with material and cross section data. This feature is necessary for the students to make their reports. As such they can copy the data without retyping, but also without any special formatting in the virtual lab, so it can be fit in any report.

\subsection{VIRTUAL LABORATORY REALISATION}

For the virtual lab realisation were used HTML5, ActionScript and JavaScript. The component diagram of developed application is presented on the Fig. 5.

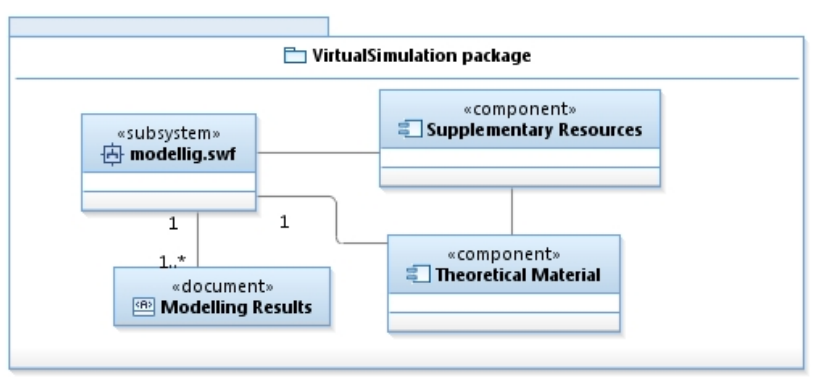

Fig. 5 - Component Diagram for Virtual Lab.

Subsystem "Modelling" is an interactive animation, based on Flash and ActionScript. Its consists of 3 components: a visual component, a component for calculations and the component showing different shapes. Such realizations make it possible to easily add new shapes. The realization of the calculation for different shapes is realized by classes put in package beam, which is part of subsystem "modelling” shown on the Fig. 6.

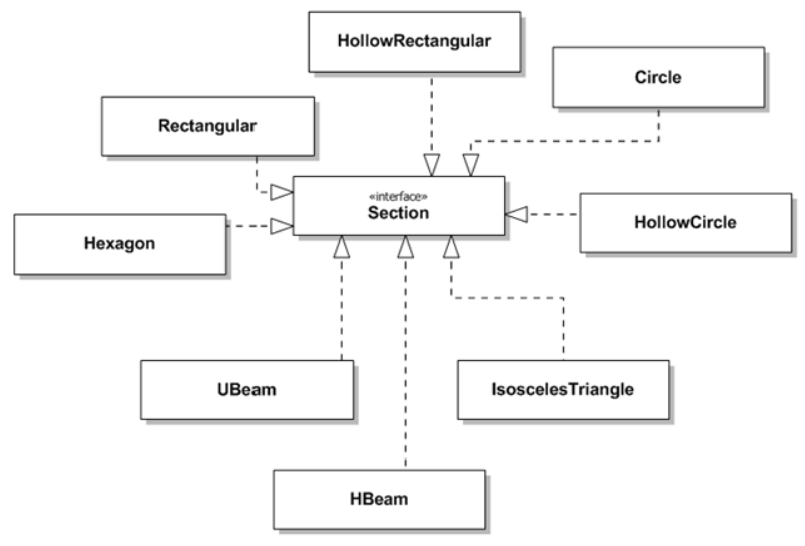

Fig. 6 - Class Diagram for the cantilever beam calculation depending from the shape.

\subsection{VIRTUAL LABORATORY FUNCTIONALITY}

To run the experiment on the client side user should use any web-browser with an installed Flash Player. The main screen of the virtual lab is in Fig. 7.

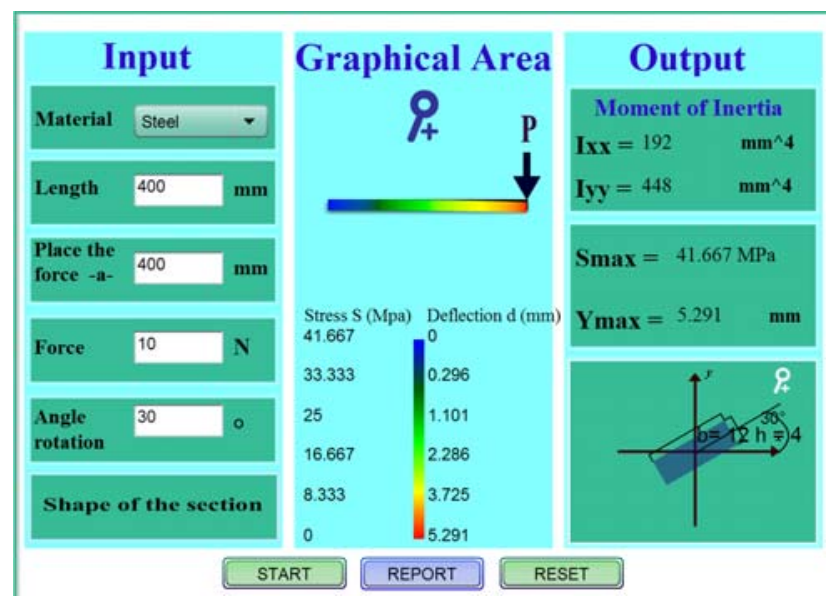

Fig. 7 - Screen shot of the actual virtual lab.

All results can be viewed in an additional window and printed (Fig. 8). The report window is a simple text window which allows the student/experimenter to copy paste these results in his lab reports, without having to type all texts.

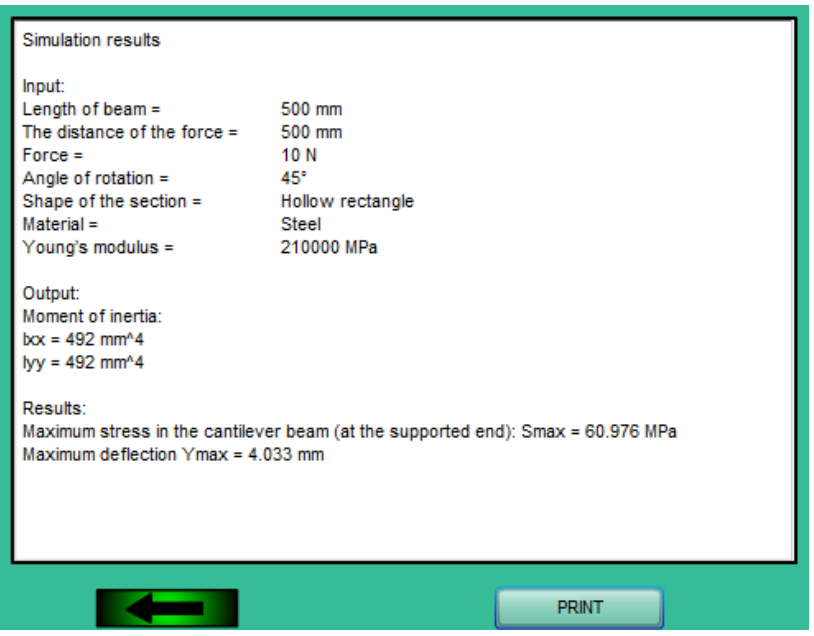

Fig. 8 - Screen shot of the report screen.

\section{REMOTE LABORATORY}

The objective of the experiment in the remote lab is similar to the objectives of the real physical lab on bending. First objective is to see and to measure the deflection of the cantilever beams. These values can be compared to the theoretical results from the virtual laboratory. Second goal of the physical lab which is substituted by the remote lab is to let students understand the influence of errors in 
measuring values on the uncertainty of their results. Students need to calculate the (possible) error on their values by means of the theory of errors, considering all sources of errors in the experiment (accuracy of tools, uncertainty of loads, distances...)

\subsection{HARDWARE CONSTRUCTION}

The construction of the experiment consist of sets of beams. The beams can be any basic shape (round, square, rectangular, hollow). The beams as deformed by pulling them with pneumatic cylinders (Fig. 9). A reading scale is attached at the front end to measure the deflection by means of a camera. The reading scale resolution is $1 \mathrm{~mm}$. The improve the read-out of the deflection, at the end of each beam, a blue marker was attached, to contrast as much as possible with the reading scale. Electronic control of the lab is with a simple relay board, on the USB-port of the computer.

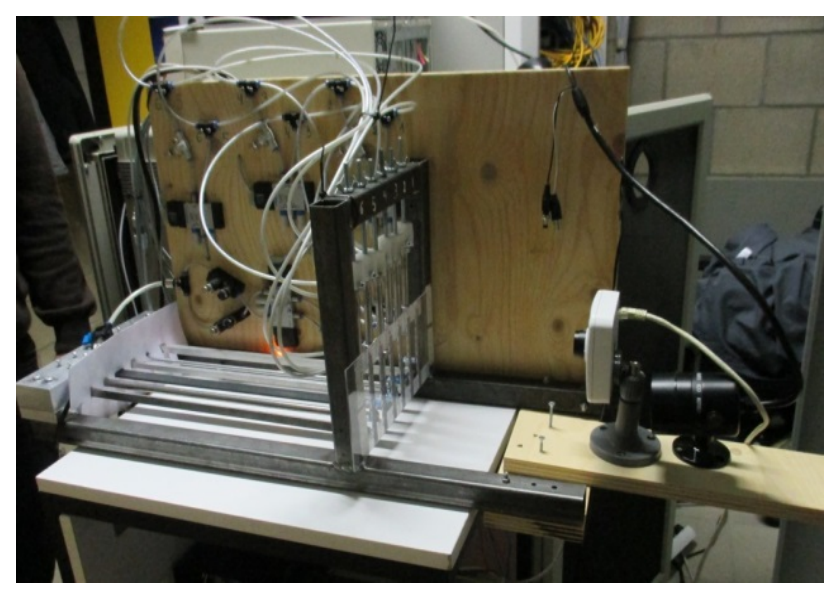

Fig. 9 - The hardware construction.
In the lab uses an IP-cam for the measurement (reading the scale) and a web-cam for board control and monitoring the deflection.

\subsection{REMOTE LABORATORY REALIZATION}

The control software driving the remote lab and integrating it in the CALM-website was developed with the collaboration with ZNTU, leading to a graphical user interface containing camera pictures and controls in one screen.

In general the software for the remote lab consists of three main subsystems:

- for control of the cameras;

- for board control;

- for lab control;

The subsystem for lab control is a controller which allows to control the process: initiate the session, safety control, process the logic of the experiment, close the session (Fig. 10).

The subsystem for board control task is for switching the relays on the relay board.

In Fig. 11 is shown the class diagram for these two subsystems.

The subsystem for camera control is an independent system, which allows to output videostreams using the rtsp-protocol and to save screenshots of the device with high resolution for further measurements. Using the rtsp-protocol allows to display the video in browser after installing the vlc-plugin.

For the realization was chosen the Spring MVC Framework. The basic logic was realized with java, for visualization were used HTML, CSS, Javascript, JQuery, JSP.

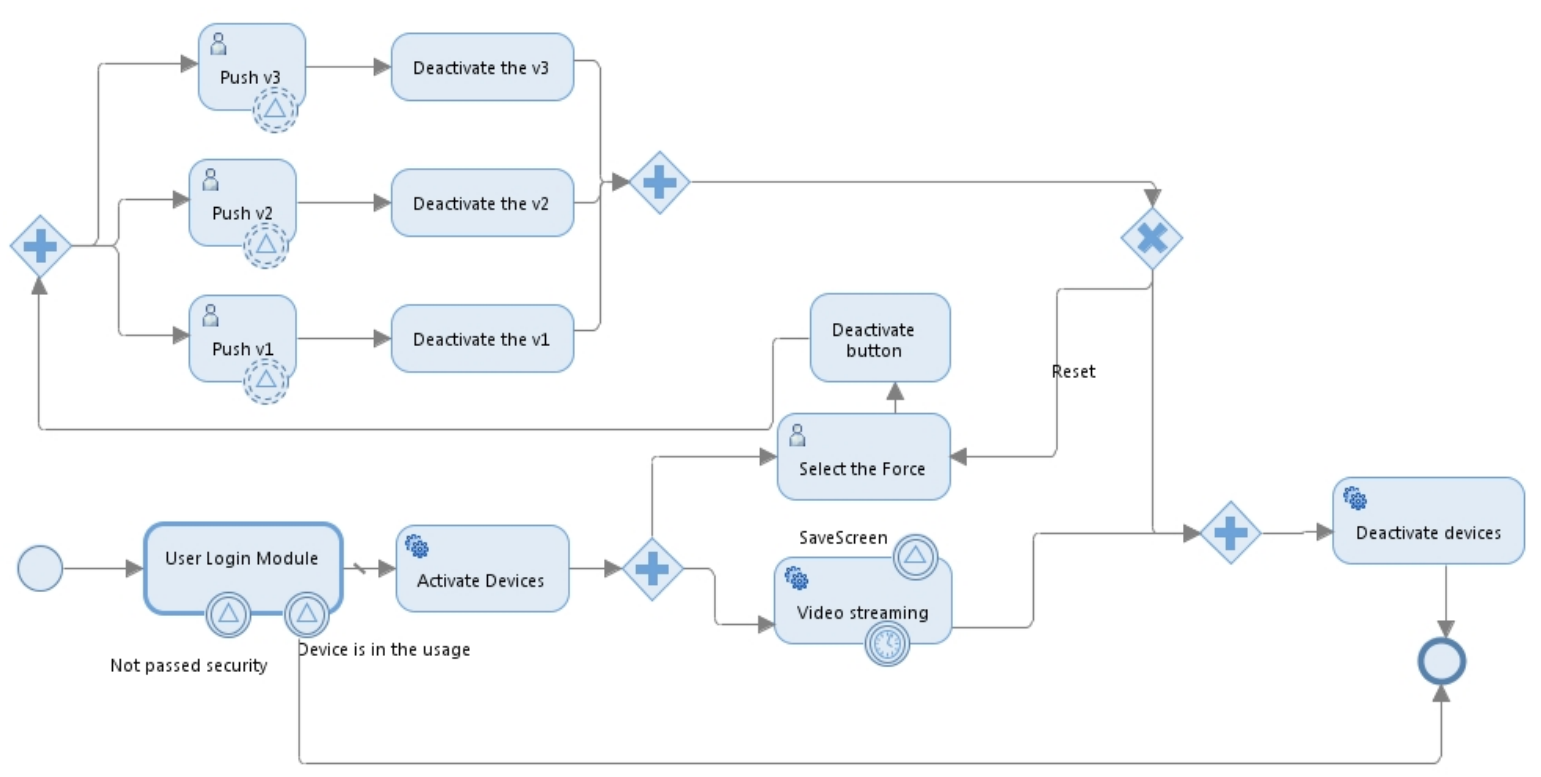

Fig. 10 - Remote Laboratory functionality. 


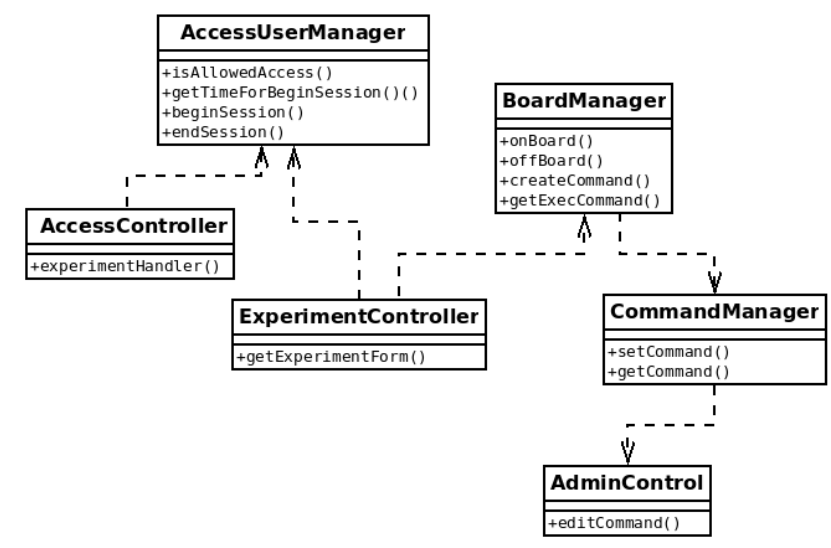

Fig. 11 - Class diagram.

\subsection{FUNCTIONALITY OF LAB-CONTROL MODULE}

After getting access to the remote lab student can choose the force applied to the beams and activate the forces on the different test specimen (beams) by pressing the different valve buttons.

To cope with possible problems on images and video, a section for saving screenshots was integrated for offline working with the experimental results. The different screenshots can be reviewed to measure the deflection at the end of the beams. As such experimenting time could be reduced to 10 minutes per student. Security measures are installed to avoid automated/hacked control of the lab.

The view of remote laboratory control through web interface can be seen in Fig. 12.

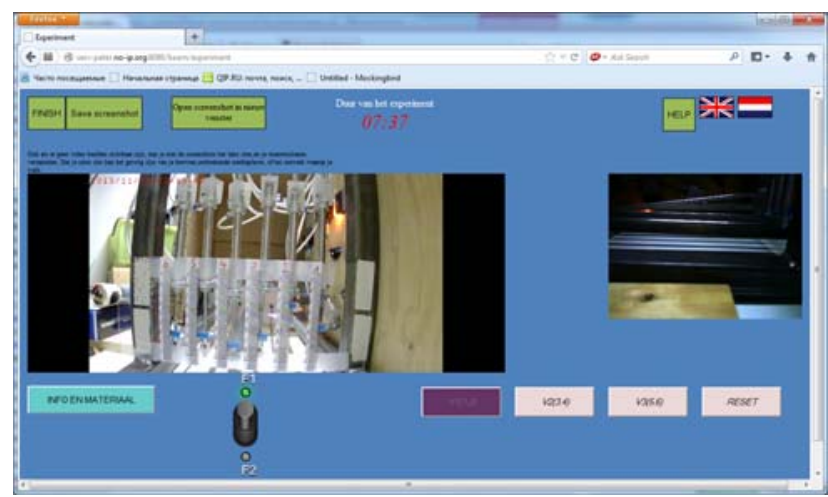

Fig. 12 - Remote Laboratory: left IP-cam for measuring, right webcam for viewing the deflection.

First evaluations of the lab show that overall functionality of the lab is appreciated by the students. Most of the problems arise with the video (speed of connection for life-streams) and the interference or no connection with plug-ins. Also the use of the lab in different browsers (Internet Explorer, Google Chrome, Firefox) show causes of ineffectiveness as all 3 browsers treat videos differently. This makes it somewhat difficult for the students, as they (sometimes) need to tune their browser first.

\section{CONCLUSION}

The blended learning approach shows the most efficient results among different approaches with the usage of e-learning systems. The developed elearning environment CALM is useful both for students needs (self-study needs) as for teachers (central source of all course related materials). It consists of different e-learning tools - html content of learning material as theoretical background and recommendations for practical tasks, tools for lecture presentation, elements of experiments with material properties simulation and remote laboratory, which give possibilities for a more practical approach to learning.

In future, new tasks on expanding the CALM are to modify the architecture to incorporate new infrastructure for other remote laboratories and to enhance the security model, as there are plans to increase number of students using the remote labs. Security is necessary to ensure the safety of the equipment and to avoid early wear or destruction by unwanted use of the remote labs.

\section{REFERENCES}

[1] P. Arras, Computer aided learning approach for the study of the Properties of Materials, Proceedings of the Conference Vzájomná informovanost' - cesta $k$ efektivnemu rozvoju vedecko-pedagogickej činnosti, 13 June 2013, Pedagogická fakulta UKF v Nitre, pp. 5-11.

[2] P. Arras, G. Tabunshchyk, T. Kozik, E-learning concept for the properties of materials remote study, Proceedings of the 2013 IEEE $7^{\text {th }}$ International Conference on Intelligent Data Acquisition and Advanced Computing Systems: Technology and Applications, Berlin, Germany, 12-14 September 2013, Vol. 2, pp. 742-747.

[3] R. C. Hibbeler, Statics and Mechanics of Materials, vol. Bending, New York: Pearson/Prentice Hall, 2004, pp. 511-544.

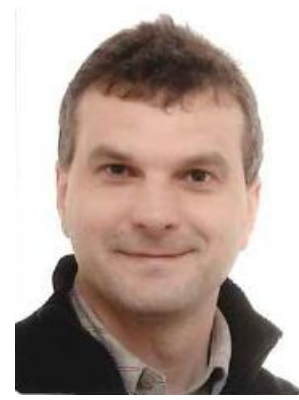

Peter Arras, drs, graduated as engineer in 1985 at De Nayer institute in Belgium. Got a pedagogical degree in 1986. Teaching design methods and numerical simulation methods in the faculty of engineering technology of KULeuven Since 2006 international studies coordinator at the department. 
Areas of interest in his scientific work are design related methods, CAD/CAM/CAE-systems, e_learning methods.

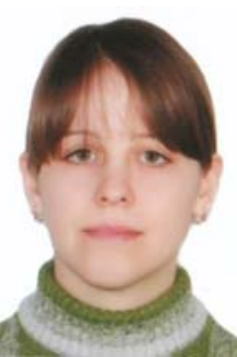

Yelizaveta Kolot - PhD student of Zaporizhzhya National Technical University, received and Engineering Diploma in Informational Technologies in Design in 2013 with qualification analytic of Informational Systems. Scientific Interests software development, reliability of informational systems.

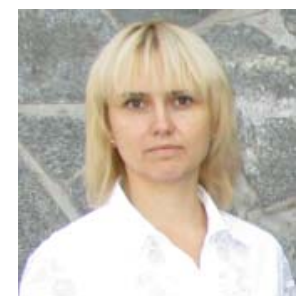

Galyna Tabunshchyk PhD, Assoc. Prof. of Software Tools Department of Zaporizhzhya National Technical University, finished Zaporizhzhya State Technical University in 1998, made her PhD work in 2004 in Control Systems and Proces-

ses. The main topics of interests are Software Engineering, System Analysis, Testing and Reliability of Computer Systems.

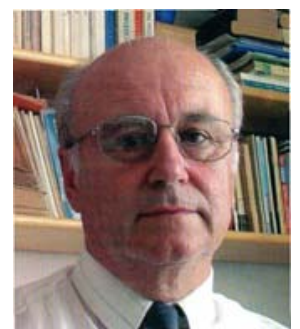

Tomaš Kozík, Prof, Ing, DrSc, graduated in physics of solid states from the Slovak University of Technology in Bratislava, Slovakia in 1968. After defending his Doctoral thesis in condensed matter physics he was granted title PhD.

In 1989 he defended his DrSc in technology of ceramic materials processing and was appointed associate professor in branch of physics of condensed compounds and acoustics at the Slovak University of Technology in Bratislava and later in 1994 full professor in branch of electrical engineering materials at the Faculty of Electrical Engineering, STU in Bratislava. Since 1990 he has been working at the Department of Technology and information Technologies, University of Constantine the Philosopher in Nitra and as an external professor at the Slovak University of Technology in Bratislava, at the Faculty of Materials Science and Technology in Trnava. His main research activities are focused on physical properties and technology of the classical and progressive ceramic materials, special glasses and plastics treatment, as well as didactics of technical vocational subjects. 